\title{
SPINOCEREBELLAR ATAXIA 1 (SCA1) IN THE JAPANESE: ANALYSIS OF CAG TRINUCLEITIDE REPEAT EXPANSION AND INSTABILITY OF THE REPEAT FOR PATERNAL TRANSMISSION
}

\author{
Yoshihiro SUZUKI, ${ }^{1, *}$ Hidenao SASAKI, ${ }^{1, * *}$ Akemi WaKISAKA, ${ }^{2}$ \\ Akio TaKada, ${ }^{2}$ Takashi Yoshikl, ${ }^{2}$ Kiyoshi Iwabuchi, ${ }^{3}$ \\ Kunio Tashiro, ${ }^{1}$ Toshiyuki FukazaWa, ${ }^{4}$ and Takeshi Hamada ${ }^{4}$ \\ ${ }^{1}$ Department of Neurology and 'Department of Pathology, Hokkaido University \\ School of Medicine, Sapporo 060, Japan \\ ${ }^{3}$ Department of Neurology and Psychiatry, Kanagawa Rehabilitation Center, Atsugi 243-01, Japan \\ ${ }^{4}$ Hokuyukai Neurological Hospital, Sapporo 063, Japan
}

\begin{abstract}
Summary SCA1 is caused by expansion of an unstable CAG triplet repeat in a novel gene located on the short arm of chromosome 6 . In 126 Japanese individuals from 12 pedigrees with SCA1, studies were done to determine if they carried this mutant gene. All the affected and presymptomatic individuals, determined by haplotype segregation analyses, carried an abnormally expanded allele with the range of 39-63 repeat units. This repeat size inversely correlated with the age at onset. However, contrary to reported results, size of the repeat did not correlate with gender of the transmitting parent. Therefore, the CAG triplet repeat instability on paternal transmission is not likely to be fundamental to SCA1.

Key Words spinocerebellar ataxia 1 (SCA1), CAG repeat, olivopontocerebellar atrophy, hereditary ataxia
\end{abstract}

\section{INTRODUCTION}

Spinocerebellar ataxia 1 (SCA1: McKusick number 16440) is a geneticaily defined disorder, separated from dominant olivopontocerebellar atrophy (OPCA). As generally seen in other types of dominant ataxias, symptoms first become evident in mid-adult life and the course is progressive with time, leading to ultimate disability. Neuronal loss and gliosis are selectively present in the cerebellar cortex, dentate nucleus, pontine nuclei, inferior olivary nucleus, motor neurons in brain stem and spinal cord, and other structures in the central nervous system (CNS). The gene locus of SCA1 was first assigned to chromosome 6p, on the basis of a

Received August 12, 1994; Revised version accepted November 25, 1994.

* Present address: Department of Internal Medicine (III), Yamagata University School of Medicine, Yamagata.

**To whom correspondence should be addressed. 
linkage with HLA (Yakura et al., 1974; Jackson et al., 1976). After demonstration of a tight linkage with D6S89 (Ranum et al., 1991; Zoghbi et al., 1991; Kwiatkowski et al., 1993), SCA1 was precisely mapped to chromosome 6p22-p23. A polymorphic CAG triplet repeat which correlates SCA1 was identified within the putative coding region (Orr et al., 1993). On the normal chromosome, this triplet usually varies by 25-36 repeats, whereas it is expanded to more than 43 repeats on the affected chromosome. There is a strong negative correlation between size of the CAG repeat and age at onset of SCA1. The entire cDNA sequence of the novel gene containing this CAG triplet repeat (SCA1 gene) has been determined recently (Banfi et al., 1994). The polymorphic CAG repeat is identified at the $5^{\prime}$ region of the coding region. The SCA1 gene is expressed in various tissues and is not limited to the CNS. How this gene relates to selective neuronal degeneration has remained unknown, because the SCA1 gene has no homology to known genes.

Based on linkage studies, we assigned SCA1 and SCA2 as major disorders in dominant OPCA in the Japanese (Sasaki et al., 1992; Ihara et al., 1994). To confirm this genetic background, we analyzed expansion of the CAG repeat in chromosome 6p-linked OPCA pedigrees.

\section{MATERIALS}

Pedigrees. Twelve pedigrees were studied (Table 1, Fig. 1), 10 were in Hokkaido and two were from Yamagata prefecture and Tokyo, respectively. In each

Table 1. SCA1 pedigrees.

\begin{tabular}{|c|c|c|c|c|c|}
\hline \multirow{2}{*}{ Family No } & \multicolumn{4}{|c|}{ Sampled individuals } & \multirow{2}{*}{ Collected from } \\
\hline & Affected & At-risk & Married-in & Total & \\
\hline P4 & 4 & $2(1)^{a}$ & 2 & 8 & Hokkaido \\
\hline P9 & 4 & $3(0)$ & 0 & 7 & Hokkaido, Tokyo \\
\hline P10 & 16 & $25(7)$ & 5 & 46 & Hokkaido \\
\hline P11 & 2 & $2(0)$ & 1 & 5 & Hokkaido \\
\hline $\mathrm{P} 13$ & 2 & $1(0)$ & 1 & 4 & Hokkaido, Tokyo \\
\hline P16 & 4 & $4(0)$ & 4 & 12 & Hokkaido \\
\hline P26 & 2 & $2(1)$ & 1 & 5 & Hokkaido \\
\hline P38 & 2 & $1(0)$ & 0 & 3 & Hokkaido \\
\hline P39 & 1 & $3(0)$ & 2 & 6 & Hokkaido \\
\hline P51 & 5 & $7(2)$ & 2 & 14 & Yamagata, Tokyo \\
\hline P52 & 2 & $4(1)$ & 2 & 8 & Yamagata, Tokyo \\
\hline P61 & 2 & $3(1)$ & 3 & 8 & Hokkaido \\
\hline Total & 46 & $57(13)$ & 23 & 126 & \\
\hline
\end{tabular}

a Figures in parentheses indicate number of pre-symptomatic individuals. 


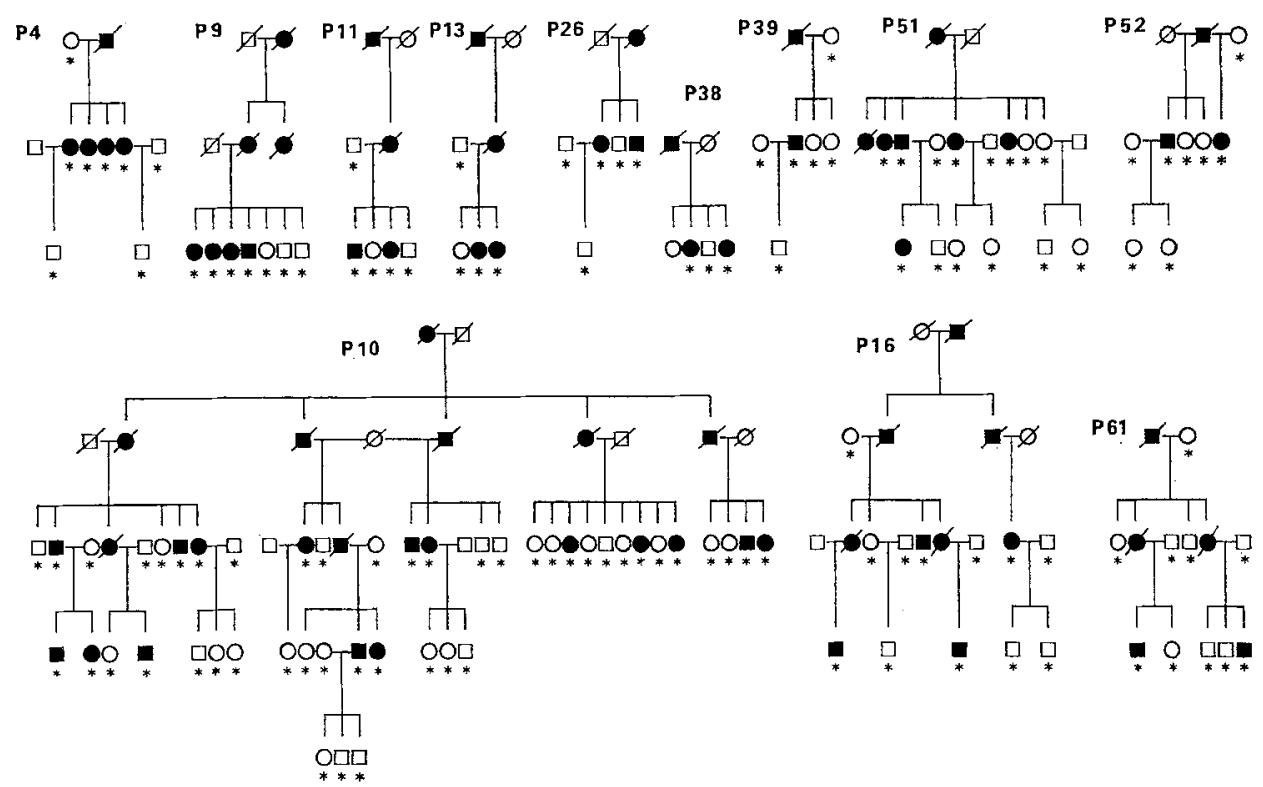

Fig. 1. Pedigree structure of SCA1 families. *Sampled individuals. $\square$, man; $\bigcirc$, woman; - and $\bullet$, affected; /, deceased.

pedigree, affected individuals were distributed over successive generations, in both sexes. These 12 pedigrees included 46 affected, 57 at risk, and 23 married-into individuals. Linkage and haplotype segregation analyses indicated that 13 of 57 at risk individuals were potentially presymptomatic and carried the mutant gene inherited from the affected parent (Wakisaka et al., under submission). All patients in each pedigree were neurologically evaluated by the authors. In addition to the results of linkage study, homogeneity of clinical and neuropathological features further indicated that they were affected with a same genetic disorder (unpublished data). Among these 12 pedigrees, general pedigree information, clinical features, and neuropathological findings were already reported for P10 (Sasaki et al., 1993; Hamada et al., 1993), P11 (Sasaki et al., 1991) and P16 (Sasaki et al., 1990). Pedigree P16 was found to be the same family as in the report of Marie's ataxia by Yakura et al. (1974), and as T-pedigree by Ikeda (1987). Age at onset was obtained for 45 living and 10 deceased patients, latter from medical records. The mean age at onset was $35.2 \pm 9.3$ (SD) years, the range being from 15 to 63 years.

Control. From 12 pedigrees, 23 married-into individuals were served as the unrelated normal controls. Additionally, we analyzed 133 patients with ataxia other than a SCA1. Since CAG repeats were not expanded on these patients, the data were incorporated into data on controls. 


\section{METHODS}

DNA source. With informed consent, $20 \mathrm{ml}$ of peripheral blood were collected from each subject. Genomic DNA was extracted from white blood cells or lymphoblastoid cell lines.

Analysis of CAG repeat. According to Orr et al. (1993), polymerase chain reaction (PCR) amplification of CAG containing segments was done with Rep-1 and Rep-2 primer pairs. These oligonucleotide primers were synthesized using a DNA synthesizer (Model 380 B, Applied Biosystems). PCR was done using a total volume of $7.5 \mu \mathrm{l}$ containing $50 \mathrm{ng}$ of genomic DNA, 0.4 pmol of each primer, $250 \mu \mathrm{M}$ dNTPs, $10 \mathrm{~mm} \mathrm{KCl}, 20 \mathrm{mM}$ Tris- $\mathrm{HCl} \mathrm{pH} 8.2,1.5 \mathrm{~mm} \mathrm{MgCl}, 2 \%$ formamide, $0.1 \%$ Triton $\mathrm{X}-100,6 \mathrm{~mm}\left(\mathrm{NH}_{4}\right)_{2} \mathrm{SO}_{4}$, and $0.5 \mathrm{U} \mathrm{Pfu}$ polymerase (Stratagene). Pep-1 primer was end-labeled with [ $\left.\gamma^{32} \mathrm{P}\right] \mathrm{ATP}$ (ICN Biomedicals), using T4 polynucleotide kinase. The PCR mixtures were then denatured at $94^{\circ} \mathrm{C}$ for $5 \mathrm{~min}$, followed by 30 cycles of denaturation at $94^{\circ} \mathrm{C}$ for $60 \mathrm{~s}$, annealing at $57^{\circ} \mathrm{C}$ for $60 \mathrm{~s}$, extension at $72^{\circ} \mathrm{C}$ for $2 \mathrm{~min}$, and elongation at $72^{\circ} \mathrm{C}$ for $7 \mathrm{~min}$. PCR products were mixed with $45 \mu \mathrm{l}$ of loading buffer ( $95 \%$ formamide, $20 \mathrm{mM}$ EDTA, $50 \mathrm{mg} / \mathrm{ml}$ of bromophenol blue, and $50 \mathrm{mg} / \mathrm{ml}$ of xylene cyanol), denatured, then cooled in iced water. Five microliters of the mixture was electrophoresed through a $6 \%$ polyacrylamide sequencing gel containing $7 \mathrm{M}$ urea, at $1,600 \mathrm{~V}$ in $1 \times \mathrm{TBE}$ buffer for $3 \mathrm{~h}$. The products were visualized by autoradiography at room temperature. To determine size of the CAG repeat, samples were co-migrated with sequenced alleles used as a index. After screening, samples showing expanded allele size were selected and electrophoresed again with the order of allele size following the index. Since the PCR product of the expanded allele was heterogeneous for CAG repeat size, the most intensely stained band on the autoradiograms was read to estimate size of the CAG repeat.

DNA sequencing. To determine the DNA sequence of normal and expanded alleles, DNA from selected individuals was amplified with Rep-1 and GCT-435 primers (Chung et al., 1993) in a total volume of $100 \mu$ l, under the PCR conditions described above. The PCR products were run on a $2 \%$ low-melting-temperature agarose gel and appropriate bands were collected. After purifying DNAs on a microspin column Suprec-01 (Takara), products were sub-cloned using PCR-Script ${ }^{(\mathbb{Q}}$ SK( + ) cloning kit (Stratagene). Both CAG and GTC strands of cloned segments were sequenced, using the dsDNA cycle sequencing system (Gibco Brl).

\section{RESULTS}

\section{Size of $C A G$ repeat of $S C A 1$ pedigrees}

In 12 pedigrees, all 46 patients and 13 presymptomatic individuals carried one large sized (expanded) and one small sized (non-expanded) alleles. A representative 


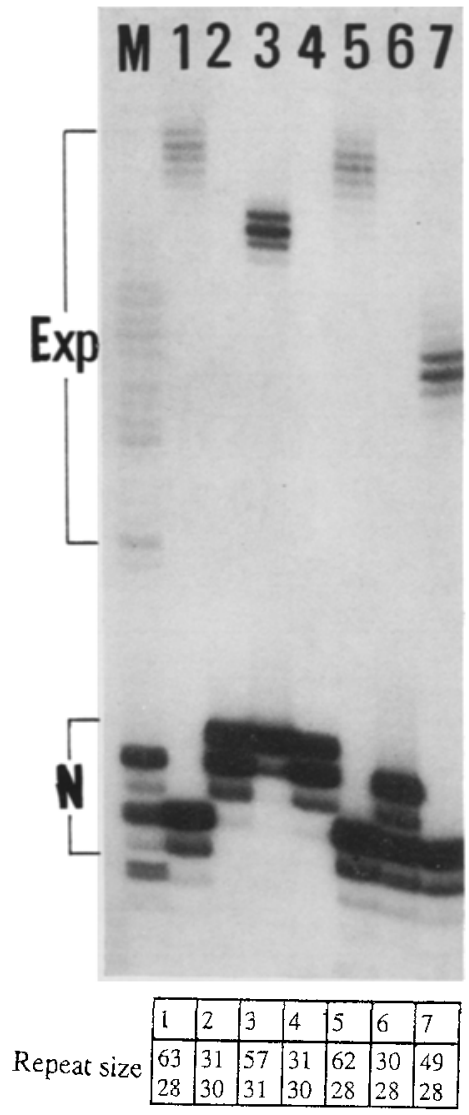

Fig. 2. Autoradiogram of PCR amplified products containing CAG repeats at SCA1 locus. Lanes 1, 3, 5, and 7 from affected individuals, and lanes 2, 4, and 6 from normal individuals. $\mathrm{M}$, marker; $\mathrm{N}$, normal alleles; Exp, expanded alleles.

example is shown in Fig. 2. The former ranged from 39-63 repeats and the latter 19-31 repeats. These expanded alleles were exclusively observed in these individuals and were never found in 44 other at risk and 23 married-into individuals. The mean size was 49.2 \pm 4.1 (SD) repeats in expanded alleles ( $\mathrm{n}=59$ SCA1 chromosomes), and $27.8 \pm 2.2$ in non-expanded alleles ( $n=193$ normal chromosomes). There was no overlap between these two groups. The repeat-size distribution of 59 expanded alleles is presented in Fig. $3 a$.

\section{Size of CAG repeat of non-SCA1 patients}

In 133 genotyped individuals from pedigrees with ataxia of miscellaneous origin, allele size ranged from 23-33 repeat units in 261 chromosomes, but alleles elongated up to 39 and 40 repeat units were detected in 3 chromosomes from a 
a

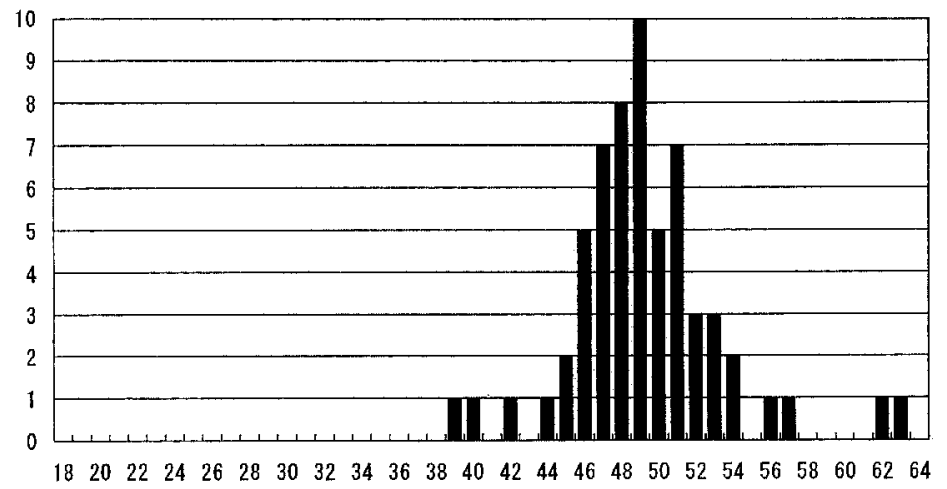

$\mathrm{b}$

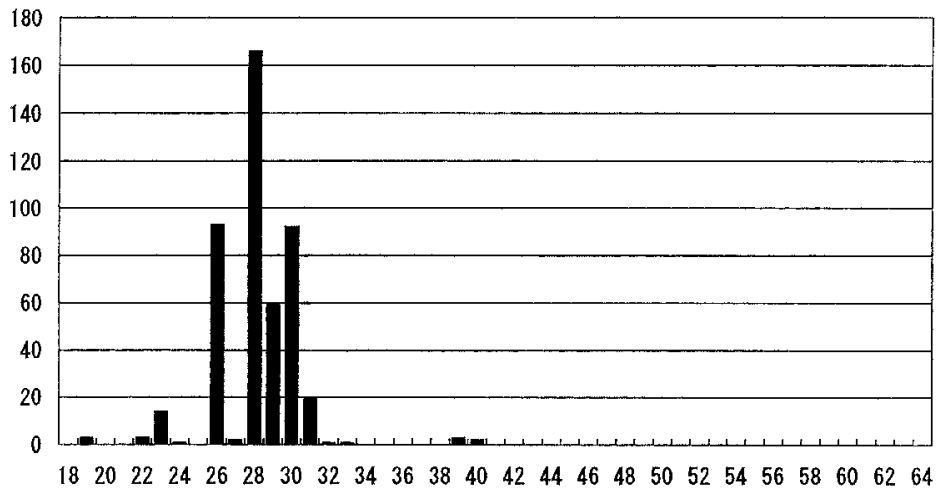

Fig. 3. Histogram of repeat number in the mutant chromosomes. 46 affected and 13 presymptomatic SCA1 chromosomes (a) and 459 normal chromosomes (b) were shown separately.

pedigree with Machado-Joseph disease and in 2 chromosomes in case of Holmes' ataxia, respectively. However, the disease did not co-segregate with either the elongated alleles or with chromosome $6 \mathrm{p}$ microsatellites in these two pedigrees. When these data (266 chromosomes) were combined with those of normal controls from SCA1 pedigrees (193 chromosomes), allele size of overall normal chromosomes ranged from 19 to 40 repeat units with the mean value of $28.1 \pm 2.3(n=459$ chromosomes). The distribution of repeat size is presented in Fig. $3 \mathrm{~b}$.

\section{Age at onset and size of repeat}

Information of age at onset was available from 45 genotyped patients. A scattergram of age at onset $v s$. repeat number of expanded alleles is given in Fig. 4. Late-onset SCA1 (age >50) individuals showed at least 40-46 repeats, while juvenile onset (age $<20$ ) showed $62-63$ units. There was a strong inverse correlation between allele size and age of onset, with a linear correlation coefficient (r) 
of $-0.78(\mathrm{p}<0.01)$.

\section{Instability of size of repeat and parental gender effect on transmission}

Size of the mutant alleles was unstable on transmission to successive generations in our SCA1 pedigrees. To evaluate this instability more precisely, we first calculated the difference of CAG repeat size of the mutant alleles among 15 parentoffspring pairs: 6 father-child and 9 mother-child pairs. The difference among these pairs distributed from -4 to +3 repeat units with the average of $-0.47 \pm$

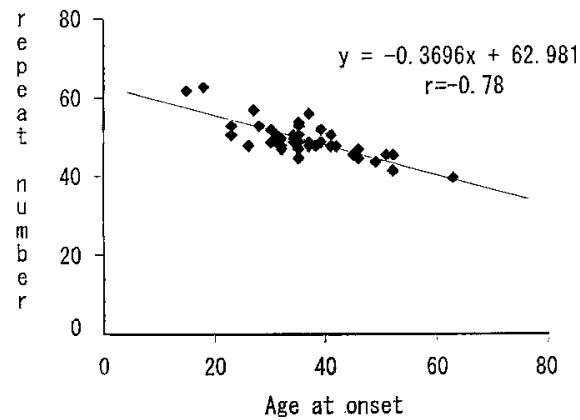

Fig. 4. Scattergram of age at onset $v s$. repeat number of expanded alleles.

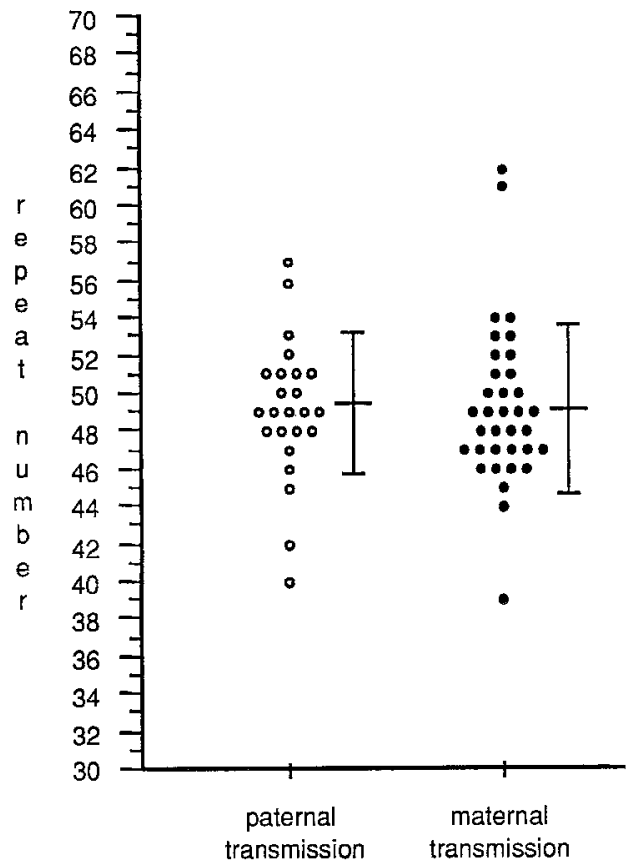

Fig. 5. Allele distribution for the CAG repeat length on SCA1 chromosomes transmitted from affected parent. 
$2.07(\mathrm{n}=15)$. When parental gender on transmission was compared, the size varied from -3 to +3 units, with the average of $0.33 \pm 2.16(n=6)$ in paternal transmission, and from -4 to +2 units with the average of $-1.00 \pm 1.94(n=9)$ in maternal transmission. There was no significant difference between the two mode of transmission.

We next examined the distribution of allele size according to gender of the affected parent. The gender of the affected patent was known for 59 subjects carrying the mutant allele. The distribution of allele size is shown in Fig. 5. The

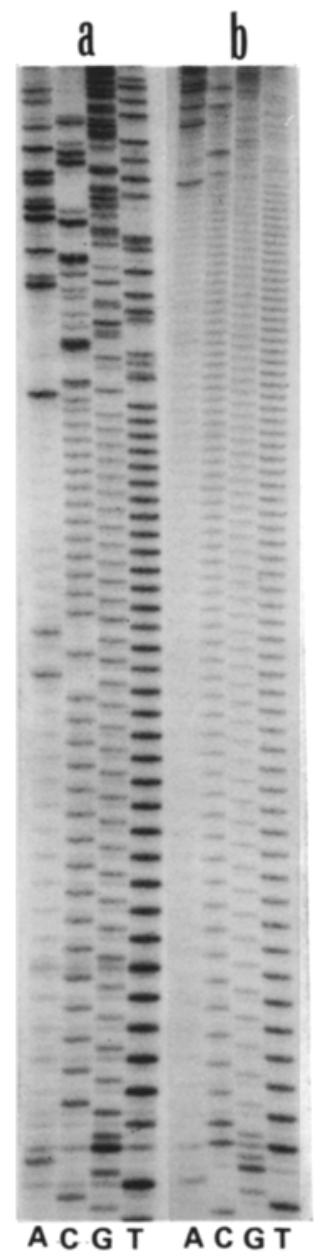

Fig. 6. DNA sequencing gels including CAG repeat of a normal allele (a) and an expanded allele (b), using primer KS. A normal allele has 2 ATG (CAT when reversed) insertions within CTG (CAG when reversed) repeat, the expanded allele has no ATG insertions. 
mean repeat number of mutant alleles was $49.1 \pm 3.7$ units $(40-57, \mathrm{n}=24$ chromosomes) for paternal origin, and $49.3 \pm 4.5$ units (39-63, $n=35$ chromosomes) for maternal transmission. No significant difference was observed between these two groups.

\section{Internal structure of alleles}

After sub-cloning of the PCR product, clones of 9 normal and 4 expanded alleles were subjected to base sequencing (Fig. 6). Consequently, all the normal alleles contained CAT or CATCAGCAT within the CAG repeat tract. An elongated normal allele of 39 repeat units was also interrupted with a CATCAGCAT sequence. On the other hand, a continuous and uninterrupted CAG repeat sequence was detected in all 4 expanded alleles from SCA1 pedigrees.

\section{DISCUSSION}

The discovery of CAG repeat polymorphism and apparent association of abnormally expanded alleles with the disease have revealed that SCA1 is a triplet repeat disorder (Orr et al., 1993). Although the motif of trinucleotide repeat unit varies among diseases, a similar expansion of triplet repeat has been identified in X-linked spinal bulbar muscular atrophy (La Spada et al., 1991), fragile X syndrome (Verkerk et al., 1991), myotonic dystrophy (Hurley et al., 1992; Mahadevan et al., 1992), Huntington's disease (The Huntington's disease collaborative research group, 1993), and more recently in dentatorubral-pallidoluysian atrophy (Koide et al., 1994; Nagafuchi et al., 1994). The present study clearly demonstrated that chromosome 6p-linked ataxia (SCA1) in the Japanese race has the same molecular abnormality.

Through analyses of SCA1 pedigrees from different ethnic origins, the range of allele size is 25-36 (Orr et al., 1993) or 26-37 repeats (Jodice et al., 1994) in normal chromosomes, and is expanded to be 43-81 (Orr et al., 1993) or 46-66 repeats (Jodice et al., 1994) in SCA1-related chromosomes. Additionally, size of the expanded allele was found to correlate inversely with the age at onset, and be unstable, especially in case of paternal transmission. Size of alleles in our Japanese subjects with SCAl was also expanded to 39-63 repeats, and negatively correlated with age at onset. These results showed common features of SCA1 beyond ethnic difference. However, there are several differences which need to be mentioned.

Firstly, the distribution of normal alleles in the Japanese differs from that in Caucasian. In our subjects the normal allele mostly ranged from 19-33 repeats ( $98.9 \%$ of all) and distribution was seen with the peak value of $28(36 \%)$, with the second peaks of $26(20.4 \%)$ and $30(20.1 \%)$ repeat units. Allele of 27 repeat units was rare $(0.4 \%)$ and that of 29 repeat units was relatively infrequent $(12.9 \%)$. Although our data were not based on random healthy controls, this tri-modal distribution is clearly different from the normal distribution with the peaks of 29-30 
repeat units obtained from Caucasians (Jodice et al., 1994). As noted from the analysis of CTG repeats at myotonic dystrophy (MD) gene (Davies et al., 1992), this difference may reflect the natural divergence of human genetic resources among different ethnic groups.

Secondary, we observed moderately expanded alleles up to 39 and 40 repeat units $(1.1 \%$ of all $)$ in chromosomes unrelated to SCA1. The values were overlapped with those of the SCA1 patients with late-onset. This overlap had not been heretofore described in the literature. However, as do in most of normal alleles, CAG repeats were interrupted with the CAT sequence in these alleles. Interestingly the overlapped alleles were found in the patients with MJD or Holmes' ataxia and its consanguinity, but not in real healthy normal controls who married into the pedigrees. Since both MJD and Holmes' ataxia are supposed to be triplet repeats disorders, this results suggest that a common mechanism may underlie in all three diseases which allows expansion of the triplet repeats. Our results also indicate that such overlap is rare, nevertheless it must be taken into account on PCR screening and carrier detection of SCA1.

Thirdly, the instability on paternal transmission is somewhat different. Since the size of abnormally expanded alleles is unstable, expansion or contraction of the repeats is frequen in intra- and inter-generations. This instability corresponds with age at onset, and clinical severity (Orr et al., 1993). In SCA1 expansion occurs more frequently through paternal transmission (Chung et al., 1993). Jodice et al. (1994) reported that of 64 expanded alleles, alleles with $>54$ repeat units were exclusively transmitted from the affected father, while alleles with $<54$ repeats were transmitted from both parents, in equal proportions. However, in our study, we obtained no supportive evidence for such paternal bias on transmission nor threshold size on the parental origin of SCA1 alleles. In our subjects, the largest expanded alleles (62 and 63 units) were transmitted from the affected mother. Although the limited number of informative parent-offspring pairs may potentially bias our findings, our results do indicate that the instability on paternal transmission is not likely to be a fundamental event in SCA1. This kind of discrepancy was not been found in a study of Huntington's disease (HD) or in a study on mytotonic dystrophy (MD). In both disorders, the effect of parental sex on the repeat instability has been clearly demonstrated even in subjects from different ethnic backgrounds. It appears that our patients and presymptomatic individuals carry a founder chromosome of Japanese SCAl (Wakisaka et al., under submission). Since our pedigrees are composed of genetically homogeneous subjects, our results do suggest that parental sex is only one factor contributing to the meiotic instability of SCA1 gene.

In triplet repeat disorders, identification of the founder chromosome saves the way for searches for ancestral mutation or the genetic origin of disorders. In $\mathrm{MD}$, analysis of linkage disequilibrium suggested that Japanese and Caucasian patients share a common ancestral pre-mutation (Yamagata et al., 1992; Imbert 
et al., 1993). However in fragile $X$ syndrome (Richards et al., 1992) and HD (MacDonald et al., 1992), founder mutations are assumed to differ among cohorts of subjects. In case of SCA1, Orr et al. (1993) reported that haplotype of microsatellites flanking SCA1 gene differed among pedigrees. This would suggest that the mutation causing SCA1 could occur independently on different chromosomes. At present, an ancestral mutation predisposing to SCA1 has not been determined. A contiguous, uninterrupted CAG repeat was found in normal alleles with 19-21 repeat units (Chung et al., 1993). Despite this same gene configuration with SCA1, such alleles do not seem to be a pre-mutation because they distribute selectively at the lower limit of normal alleles. On the other hand, analysis of a new mutation in the HD gene strongly indicates that pre-mutation does occur from a pool of normal alleles with limited instability, but having repeats larger than those of typical normal alleles (Goldberg et al., 1993). In SCA1, CAT interruption within the CAG repeat tract is considered to stabilize an SCA1 allele on replication (Chung et al., 1993). Therefore, expansion of CAG repeats with the subsequent loss of CAT interruption is the most likely explanation for generation of the mutant gene. Moderately expanded alleles with CAT interruption, as found in our study, may be a pre-mutation and may constitute a reservoir for new SCAl mutation.

Acknowledgments We are grateful to members of the families of the patients for participation in this study. We thank $\mathrm{K}$. Masuda with technical assistance in the DNA analysis, Drs T. Yanagihara, K. Yoshida (Department of Neurology, Hokkaido University School of Medicine), K. Shima, S. Doi (Sapporo Minami National Hospital), A. Takei (Hokuyukai Neurological Hospital), and others for contributions to this work. This work was supported by a Grant-in-Aid for Scientific Research on Priority Areas, Ministry of Education, Science and Culture, Japan, Grant-in-Aid for Intractable Disease, Minitsry of Health and Welfare, Japan, and Suhara Memorial Foundation.

\section{REFERENCES}

Banfi S, Servadio S, Chung M, Kwiatkowski TJ Jr, McCall AE, Duvick LA, Shen Y, Roth EJ, Orr HT, Zogbbi HY (1994): Identification and characterization of the gene causing type 1 spinocerebellar ataxia. Nature Genet 7: 513-519

Chung M, Ranum LPW, Duvick LA, Servadio A, Zoghbi HY, Orr HT (1993): Evidence for a mechanism predisposing to intergenerational CAG repeat instability in spinocerebellar ataxia type 1. Nature Genet 5: 254-258

Davies J, Yamagata H, Shelbourne P, Buxton J, Ogihara T, Nokelainen P, Nakagawa M, Williamson R, Johnson K, Miki T (1992): Comparison of the myotonic dystrophy associated CTG repeat in European and Japanese populations. J Med Genet 29: 766-769

Goldberg YP, Kremer B, Andrew SE, Theilmann J, Graham RK, Squitieri F, Telenius H, Adam S, Sajoo A, Starr E, Heiberg A, Wolff G, Hyden M (1993): Molecular analysis of new mutations for Huntington's disease: intermediate alleles and sex of origin effects. Nature Genet 5: 174-179

Hamada K, Fukazawa T, Yanagihara T, Hamada T, Yoshida K, Sasaki H, Tashiro K (1993): Neuropathological study of autosomal dominant ataxia linked to loci on chromosome $6 \mathrm{p}$ (SCA1). Brain Nerve 45: 1045-1049

Hurley HG, Brook JD, Rundle SA, Crow S, Reardon W, Buckler AJ, Harper PS, Housman DE, 
Shaw DJ (1992): Expansion of an unstable DNA region and phenotypic variation in myotonic dystrophy. Nature 355: 545-546

Ihara T, Sasaki H, Wakisaka A, Takada A, Yoshiki T, Matsuura T, Hamada T, Suzuki Y, Tashiro K (1994): Genetic heterogeneity of dominantly inherited olivopontocerebellar atrophy (OP$\mathrm{CA}$ ) in the Japanese: linkage study of two pedigrees and evidence for the disease locus on chromosome 12q (SCA2). Jpn J Human Genet 39: 305-313

Ikeda T (1987): Peculiar forms of familial olivo-ponto-cerebellar atrophy (Menzel type) and Joseph disease: clinico-neuropathological study of two families with nosological considerations. Psychiatr Neurol Jpn 89: 245-281

Imbert G, Kretz C, Johnson K, Mandel J-L (1993): Origin of the expansion mutation in myotonic dystrophy. Nature Genet 4: 72-76

Jackson JF, Currier RD, Terasaki PI, Morton NE (1976): Spinocerebellar ataxia and HLA linkage. Risk prediction by HLA typing. N Engl J Med 296: 1138-1141

Jodice C, Malaspina P, Persichetti F, Novelletto A, Spadaro M, Giunti P, Morocutti C, Terrenato L, Harding AE, Frontali M (1994): Effect of trinucleotide repeat length and parental sex on phenotypic variation in spinocerebellar ataxia 1. Am J Hum Genet 54: 959-965

Koide R, Ikeuchi T, Onodera O, Tanaka H, Igarashi S, Endo K, Takahashi H, Kondo R, Ishikawa A, Hayashi T, Saito M, Tomoda A, Miike T, Naito H, Ikuta F, Tsuji S (1994): Unstable expansion of CAG repeat in hereditary dentatorubral-pallidoluysian atrophy (DRPLA). Nature Genet 6:9-13

Kwaitkowski TJ Jr, Orr HT, Banfi S, McCall AE, Jodice C, Persichetti F, Novelletto A, LeBorgneDeMarquoy F, Duvick LA, Frontali M, Subramony SH, Beaudet AL, Terrenato L, Zoghbi HY, Ranum PW (1993): The gene for autosomal dominant spinocerebellar ataxia (SCA1) maps centromeric to D6S89 and shows no recombination, in nine large kindreds, with a dinucleotide repeat at the AM10 locus. Am J Hum Genet 53: 391-400

La Spada AR, Wilson EM, Lubahn DB, Harding AE, Fishbeck KH (1991): Androgen receptor gene mutation in X-linked spinal bulbar muscular atrophy. Nature 352: 77-79

MacDonald ME, Novelletto A, Lin C, Tangle D, Barnes G, Bates G, Taylor S, Allitto B, Altherr M, Myers R, Lehrach H, Collins FS, Wasmuth JJ, Frontali M, Gusella JF (1992): The Huntington's disease candidate region exhibits many different haplotypes. Nature Genet 1: 99 103

Mahadevan M, Tsilfidis C, Sabourin L, Shutler G, Amemiya C, Jansen G, Neville C, Narang M, Barcelo J, O'Hoy K, Leblond S, Earle-Macdonald J, de Jong PJ, Wiernga B, Korneluk RG (1992): Myotonic dystrophy mutation: An unstable CTG repeat in the $3^{\prime}$ untranslated region of the gene. Science 255: 1253-1255

Nagafuchi S, Yanagisawa H, Sato K, Shirayama T, Ohsaki E, Bundo M, Takeda T, Tadokoro K, Kondo I, Murayama N, Tanaka Y, Kikushima H, Umino K, Kurosawa H, Furukawa T, Nihei K, Inoue T, Sano A, Komure O, Takahashi M, Yoshizava T, Kanazawa I, Yamada M (1994): Dentatorubral and pallidoluysian atrophy expansion of an unstable CAG trinucleotide on chromosome 12p. Nature Genet 6: 14-18

Orr HT, Chung M, Banfi S, Kwiatkowski TJ Jr, Servadio A, Besıdet AL, McCall AE, Duvick LA, Ranum LPW, Zoghbi HY (1993): Expansion of an unstable trinucleotide CAG repeat in spinocerebellar ataxia type 1. Nature Genet 4: 221-226

Ranum LPW, Duvick LA, Rich SS, Schut LJ, Litt M, Orr HT (1991): Localization of the autosomal dominant HLA-linked spinocerebellar ataxia (SCA1) locus, in two kindreds, within an 8-cM subregion of chromosome 6p. Am J Hum Genet 49: 31-41.

Richards RI, Holman K, Friend K, Kremer E, Hillen D, Staples A, Brown WT, Goonewardena P, Tarleton J, Schwartz C, Sutherland GR (1992): Evidence of founder chromosomes in fragile $X$ syndrome. Nature Genet 1: 257-260

Sasaki H, Hamada T, Wakisaka A, Tashiro K (1990): A clinical study of a family affected with 
HLA-linked hereditary spinocerebellar ataxia. Brain Nerve 42: 1103-1111

Sasaki H, Fukazawa T, Hamada K, Wakisaka A, Hamada T, Tashiro K (1991): Genetic heterogeneity of dominant olivopontocerebellar atrophy-Genetic and clinico-pathological study for an affected pedigree. Neuropathology 11: $179-188$

Sasaki H, Wakisaka A, Tashiro K, Hamada T, Shima K, Hashimoto K (1992): Linkage study of hereditary olivopontocerebellar atrophy in the Japanese: evidence for genetic heterogeneity. Clin Neurol 32: 17-22

Sasaki H, Wakisaka A, Koyama T, Hamada T, Shima K, Tashiro K, Hashimoto K, Miyagishi T (1993): Spinocerebellar ataxia $1-$ Clinical study of 17 patients in a large pedigree. Brain Nerve 45: 502-508

The Huntington's disease collaborative research group (1993): A novel gene containing a trinucleotide repeat that is expanded and unstable on Huntington's disease chromosome. Cell 72: 971-983

Verkerk AJMH, Pieretti M, Sutcliffe JS, Fu YH, Kuhl DPA, Pizzuti A, Reiner O, Richards S, Victria MF, Zhang F, Eussen BE, van Ommen G-J B, Blonden LAJ, Riggins GJ, Chastain JL, Kunst CB, Galjaard H, Caskey CT, Nelson DL, Oostra BA, Warren ST (1991): Identification of a gene (FMR1) containing a CGG repeat coincident with a breakpoint cluster region exhibiting length variation in fragile X syndrome. Cell 65: 905-914

Wakisaka A, Sasaki H, Takada A, Fukazawa T, Yanagihara T, Takei A, Suzuki Y, Hamada T, Iwabuchi K, Tashiro K, Yoshiki T (1990): Spinocerebellar ataxia 1 (SCA1) in the Japanese: putative founder effect determined by linkage disequilibrium (under submission)

Yakura H, Wakisaka A, Fujimoto S, Itakura K (1974): Hereditary ataxia and HLA genotypes. New Engl J Med 291: 154-155

Yamagata H, Miki T, Ogihara T, Nakagawa M, Higuchi I, Osame M, Shelbourne P, Davis J, Johnson K (1992): Expansion of unstable DNA region in Japanese mytotonic dystrophy patients. Lancet 339: 692

Zoghbi HY, Jodice C, Sandkuijl LA, Kwiatkowski TJ Jr, McCall AE, Huntoon SA, Lulli P, Spadaro M, Litt M, Cann HM, Frontali M, Terrenato L (1991): The gene for autosomal dominant spinocerebellar ataxia (SCA1) maps telomeric to the HLA complex and is closely linked to the D6S89 locus in three large kindreds. Am J Hum Genet 49: 23-30 